\title{
Prevalence of Gastroesophageal Reflux Disease Symptoms in a Jamaican Population
} DS Braham ${ }^{1}$, MO Mills ${ }^{1}$, MG Lee ${ }^{1}$, EF Brown ${ }^{1}$, G Gordon-Strachan ${ }^{2}$

\begin{abstract}
Objectives: Gastroesophageal reflux disease (GERD) is one of the most common conditions seen in general medical practice which is associated with an impaired quality of life. This study determined the prevalence of GERD symptoms in a Jamaican population
\end{abstract}

Methods: Eligible individuals between the ages of 18-75yrs, were invited to complete a questionnaire which included demographic data as well as the frequency and severity of typical GERD symptoms.

Results: The questionnaire was completed by 422 subjects with $51 \%$ males and $49 \%$ females. The prevalence of any GERD symptoms within the previous year was $71.1 \%$. Females were more frequently affected, $75.7 \%$, compared to $67.3 \%$ of males. Weekly symptoms was present in $18.6 \%$. Symptoms of moderate or greater severity were reported in $11.7 \%$. The most common and bothersome symptom experienced was heartburn. Nocturnal symptoms that awaken the affected subjects occurred in $17.8 \%$. GERD was strongly associated with food, supine posture and heavy meals $(\mathrm{p}<0.0001)$. There was no significant association with GERD and age or BMI. In persons with GERD symptoms, $24.2 \%(\mathrm{P}=0.000)$ saw a doctor for their symptoms and $38.6 \%$ took medication for their symptoms $(\mathrm{p}<0.0001)$ which included prescription medications in $42.7 \%$, over the counter medications in $36.3 \%$ and combination of both in $15.3 \%$

Conclusions: Symptoms of GERD are common and significant problem in the Jamaican population studied. Heartburn was the most bothersome symptom reported. Medications were taken by over one-third of symptomatic persons.

Keywords: Disease, gastroesophageal, heartburn, Jamaica, reflux. 
From: ${ }^{1}$ Department of Medicine and the ${ }^{2}$ Faculty of Medical Sciences, The University of the West Indies, Mona, Jamaica

Correspondence: Professor MG Lee, Department of Medicine, The University of the West Indies, Mona, Jamaica; e-mail: michael.lee@uwimona.edu.jm.

\section{INTRODUCTION}

Gastroesophageal reflux disease (GERD) is one of the most common conditions seen in general medical practice and presenting to the gastroenterologist (1). The prevalence of weekly symptoms of GERD in Europe was $10-20 \%$ but lower in Asia at less than 5\% (2). The prevalence of GERD symptoms in the Swedish population was $40 \%$ with a $15 \%$ prevalence of erosive esophagitis in patients undergoing endoscopy (3).

GERD is a significant contributor to the burden of health care costs and results in a significant loss of productivity (4). It also significantly affects the quality of life in patients in their productive years even with once weekly episodes and without esophagitis (5). Subjects with frequent symptoms experienced greater quality of life impairment than those in whom symptoms were less frequent or absent (5). The diagnosis of GERD is largely clinical and is based on typical symptoms. In fact, a presumptive diagnosis of GERD can be made with the presence of typical symptoms of heartburn and reflux (1). Questionnaires, to elucidate the frequency of symptoms, have been used in several populations to estimate the prevalence of GERD with acceptable specificity and sensitivity (2).

In a previous study, $44 \%$ of controls and $29 \%$ of HIV patients had reported heartburn in Jamaica (6). However, a larger study looking specifically at the prevalence of reflux symptoms is needed to determine if gastroesophageal reflux disease is a significant medical problem in the Jamaican population 


\section{SUBJECTS AND METHODS}

Subjects for the study were randomly selected from employees and visitors at the University Hospital of the West Indies (UHWI) in Jamaica. The UHWI is an academic teaching hospital and tertiary referral hospital with approximately 600 beds.

Study collaborators obtained informed consent from all subjects for the study and administered questionnaires to individuals between the ages of 18 to 75 years who were eligible for the study. Subjects included doctors, nurses, clerical staff, ancillary workers, porters and students, as well as persons accompanying or visiting patients at the UHWI. Study participants included persons entering the casualty department, the medicine and surgery clinic waiting area or any of the 20 wards at the UHWI. Every third $\left(3^{\text {rd }}\right)$ person was eligible to participate in the study. The participants were approached to participate in the study until 400 questionnaires had been completed.

Data was gathered in the form of a questionnaire. The questionnaire was administered by one of the study collaborators and completed by each individual. The questionnaire was left with the individual to be completed and collected immediately after the person was finished or the study collaborator read through the questionnaire with the individual and assisted him/her to complete it. The instrument captured demographic data as well as the frequency of typical reflux symptoms, investigations performed and medications taken. 
Persons admitted to the wards or attending for any service at the hospital were excluded from the study. The study protocol was approved by the Ethics Committee of the University of the West Indies/UHWI. Raosoft software was used to calculate the sample size using a 5\% margin of error, $95 \%$ confidence interval, population size of 20,000 and response distribution of 40\%. The recommended sample size was 363 individuals. The study aimed to complete 400 questionnaires.

The data obtained from the questionnaire was analyzed using descriptive univariate analysis (frequency tables and appropriate graphs) as well as a series of cross-tabulations and chi squared (or Fisher's Exact) tests. Data was entered and analyzed using SPSS version 16.0 for Windows.

\section{RESULTS}

There were 429 persons entered into the study, however there was missing data in 7 questionnaires which were excluded and thus the final study population consisted of 422 subjects with $51 \%$ males and $49 \%$ females.

One-third (32.9\%) of participants were in the 26-35 year old age group and a quarter (25.4\%) in the 36-45 year old group. Thirty nine percent of persons had a normal BMI and 35\% were overweight $(\mathrm{p}=0.214)$. The median BMI for persons with GERD symptoms versus asymptomatic respondents was 25.1 and 25.5 respectively.

The prevalence of any GERD symptoms was $71 \%$ within the previous year. The highest prevalence was in the 26 to 35 years old group, followed by $36-45$ and 18-25 years old, ( $\mathrm{p}=$ 0.415). The prevalence of weekly symptoms of GERD was $18.6 \%$. Moderate to severe 
symptoms weekly was $11.7 \%$. Females were more frequently affected by symptoms of GERD, $75.7 \%$ compared to $67.3 \%$ of males who had symptoms within the past year, $(\mathrm{p}=0.055)$. Nocturnal symptoms that awaken subjects occurred in $17.8 \%$ of patients.

The most common symptom experienced was heartburn (burning in the chest retrosternally) with a cumulative percent of $72.2 \%$. Reflux was reported by $68.2 \%$ and acid taste in throat in $67.7 \%$ $(\mathrm{p}<0.0001)$. The least common symptom was dysphagia in $11.7 \%$ (Table 1). Symptoms were considered to be mild in $24.7 \%$ ( $\mathrm{p}=0.011$ ) who reported burning in the chest retrosternally, $16.4 \%(\mathrm{p}=0.014)$ who reported reflux, $13.5 \%(\mathrm{p}=0.023)$ reporting acid in the throat and 7.9.\% $(\mathrm{p}=0.014)$ of persons that reported food reflux (Table 2). Food aggravated GERD symptoms was present in 70.7\%; $(\mathrm{p}<0.0001)$ of cases. Greasy food aggravated GERD symptoms in $48.8 \%$ $(\mathrm{p}<0.0001)$, followed by meats and/or beans in $18.6 \%(\mathrm{p}<0.0001)$, alcohol in $14.6 \%(\mathrm{p}<0.0001)$ and fruits in $11.9 \%(\mathrm{p}=0.014)$ of persons. Lying down after meal was associated with symptoms in $48.5 \%$ ( $\mathrm{p}<0.0001$ ) followed by having a heavy meal in $35.9 \%(\mathrm{p}<0.0001)$ and lifting in $13.6 \%$ $(\mathrm{p}=0.001)$ of participants.

Of persons with GERD symptoms $24.2 \%(\mathrm{P}=0.000)$ saw a doctor for their symptoms whilst $12.1 \%$ of persons had investigations done. Blood tests were requested in $69.4 \%$ whilst $16.1 \%$ had a barium meal and $4.8 \%$ had endoscopy.

In persons with GERD symptoms, $38.6 \%$ took medication for their symptoms $(\mathrm{p}<0.0001)$. Of subjects taking medications, prescription medications were taken in $42.7 \%$, over the counter medications in $36.3 \%$, combination of both in $15.3 \%$ and home remedy in $5.6 \%$ ( $\mathrm{p}=0.005)$. Other oral medication were taken by $27 \%(\mathrm{p}=0.022)$ of participants, $7.5 \%(\mathrm{p}=0.361)$ were taking anti-hypertensives, $4.4 \%(\mathrm{p}=0.174)$ were taking pain medications and $2.4 \%(\mathrm{p}=0.943)$ aspirin. 
There was no significant association between smoking and GERD symptoms, as in those who smoked, $10.6 \%$ had symptoms whilst $8.5 \%$ were without GERD symptoms $(\mathrm{p}=0.519)$. In persons with symptoms of GERD, $4.4 \%$ reported missing work because of their symptoms.

\section{DISCUSSION}

The diagnosis and initial management of GERD is based on symptoms, but the frequency of symptoms that constitutes disease is not well defined $(1,4)$. Most studies on GERD refer to weekly or at least weekly symptoms of gastro-oesophageal reflux (2). The prevalence of GERD symptoms on a weekly basis in this study was $18.6 \%$. Moderate to severe symptoms occurred on a weekly basis in $11.7 \%$. This is comparable to other studies as the prevalence of heartburn and/or acid regurgitation experienced at least weekly was $14 \%$ in one study and $19.8 \%$ in another $(5,7)$. In a third study, $9 \%$ of responders had experienced heartburn on that day, $15 \%$ the preceding week, $21 \%$ the previous month and $27 \%$ within the year. There was a higher overall prevalence of regurgitation, $5 \%$ for the day of response, $15 \%$, within the prior week, $29 \%$ prior month and $45 \%$ prior year (8). Although GERD appears to be increasing in prevalence in the Western world, in contrast, the reported population prevalence of reflux symptoms in eastern Asia ranged from $2.5 \%$ to $6.7 \%$ for at least weekly symptoms of heartburn and/or acid regurgitation $(9,10)$.

In the present study, the most common symptom experienced was heartburn with a frequency of $72.2 \%$. Heartburn is a relatively common symptom in Europe ranging from a prevalence of $38 \%$ in Northern Europe to $9 \%$ in Italy. Data from the USA suggests an even higher prevalence of $42 \%$ overall and weekly in $19.8 \%(7,9)$. However, in China, $3.1 \%$ reported weekly heartburn (2). In a previous smaller study in Jamaica, $44 \%$ of a control population 
experienced heartburn symptoms (6). In a study using $\mathrm{pH}$ testing, only heartburn (68\% vs 48\%) and acid regurgitation (60\% vs $48 \%$ ) occurred in more of the patients with GERD than of those with normal $\mathrm{pH}$ monitoring (11).

The present study did not demonstrate a significant relationship between BMI and GERD, but other studies have shown an increasing prevalence of GERD was associated with excess body mass/higher body mass index (BMI) (2). In a meta analysis, obesity was associated with a statistically significant increase in the risk for GERD symptoms, erosive esophagitis, and esophageal adenocarcinoma. The risk for these disorders seems to progressively increase with increasing weight (12). Other studies have found that younger females with lower BMI tend to have non-erosive reflux disease (NERD), whilst persons with esophagitis had increased age and BMI and were more likely to have continuous symptoms and require acid suppression (9).

GERD and nocturnal symptoms are associated with poor quality of life and the impairment may be comparable with that for heart disease $(4,9)$. In addition, symptom severity and nocturnal heartburn are significantly associated with reduced work productivity, particularly when nocturnal heartburn interferes with sleep (4). In one study, over $48 \%$ of respondents with severe symptoms reported reduced productivity, compared with $40 \%$ and $12 \%$ of respondents with moderate and mild symptoms, respectively and nocturnal GERD symptoms were an important predictor of reduced work productivity (4). Nocturnal symptoms occurred in $17.8 \%$ of our patients. This is slightly more than the $10 \%$ obtained in a previous study in which quality of life impairment was exacerbated in those who report nocturnal GERD symptoms (13). In addition, meaningful daytime sleepiness was also observed in individuals with GERD symptoms (14). 
In this study, $24.2 \%$ of persons with GERD symptoms actually sought medical attention and $4 \%$ reported missing work because of their symptoms. This indicate an adverse effect on productivity and cost. A previous study on GERD found that only 5\% of the population surveyed had consulted their doctor in the previous year because of GI symptoms (5). Most persons with heartburn and reflux symptoms have mild or occasional symptoms and do not seek medical advice but treat themselves with over the counter medications (15). In the present study, over one-third took medications for their symptoms, $42.7 \%$ reported taking prescription medication and $36.3 \%$ over the counter medication. In addition to an adverse effect on the quality of life, GERD is associated with the added expense of long term treatment.

Of the $24.2 \%$ of persons that sought medical attention, $12.1 \%$ had tests done. In an earlier study, medication, most commonly antacids, was used by $16 \%$ of symptomatic people, and only $5.5 \%$ had sought medical advice for symptoms during the past year (8). Based on the American college of Gastroenterology (ACG) guidelines for the diagnosis and management of GERD, a presumptive diagnosis of GERD can be established in the setting of typical symptoms of heartburn and regurgitation and empiric medical therapy with a proton pump inhibitor is recommended in this setting (1). Endoscopy is recommended in the presence of alarm symptoms and for screening of patients at high risk for complications, the elderly and non-responders to therapy (1). Esophageal manometry and 24hr esophageal $\mathrm{pH}$ monitoring are only indicated for unclear or refractory cases and to confirm the diagnosis in operative management of GERD. There were limitations in the present study. This study was a questionnaire-based study and is thus subject to recall bias. The symptoms of GERD (heartburn and acid regurgitation) are of low sensitivity but high specificity when they are the dominant complaint and therefore may not exclude other causes. 
In conclusion, this study demonstrated that symptoms of GERD are common and significant problem in our population. Weekly symptoms was present in $18.6 \%$. Symptoms of moderate or greater severity were reported in $11.7 \%$. Nocturnal symptoms occurred in $17.8 \%$. Of persons with GERD symptoms, 24.2\% saw a doctor for their symptoms and 38.6\% took medication for their symptoms which included prescription medications in $42.7 \%$, over the counter medications in $36.3 \%$ and combination of both in $15.3 \%$ 


\section{REFERENCES}

1. Katz OP, Gerson LB, Vela MF. Guidelines for the Diagnosis and Management of Gastroesophageal Reflux Disease. Am J Gastroenterol 2013; 108: 308- 28.

2. Dent J, El-Serag HB, Wallander MA, Johansson S. Epidemiology of gastro-oesophageal reflux disease: a systematic review. Gut 2005; 54: 710-7.

3. Ronkainen J, Aro P, Storskrubb T, Johansson SE, Lind T, Bolling-Sternevald E, et al. High prevalence of gastroesophageal reflux symptoms and esophagitis with or without symptoms in the general adult Swedish population: a Kalixanda study report. Scand J Gastroenterol. 2005; 40: 275-85.

4. Dean BB, Crawley JA, Schmitt CM, Wong J, Ofman JJ. The burden of illness of gastrooesophageal reflux disease: impact on work productivity. Alimentary Pharmacology \& Therapeutics 2003; 17: 1309-17 DOI: 10.1046/j.1365-2036.2003.01588.x.

5. Ronkainen J, Aro P, Storskrubb T, Lind T, Bolling-Sternevald E, Junghard O et al. Gastro-oesophageal reflux symptoms and health-related quality of life in the adult general population - the Kalixanda study. Aliment Pharmacol Ther 2006; 23(12):172533.

6. T Thompson, M. G Lee, T Clarke, M Mills, G Wharfe, C Walters. Prevalence of Gastrointestinal Symptoms among Ambulatory HIV Patients and a Control Population. Ann Gastroenterol 2012; 25: 1-6. 
7. Locke GR, Talley NJ, Fett SL, Zinsmeister, AR, Melton LJ. et al. Prevalence and clinical spectrum of Gastroesophageal reflux : A population-based study in Olmsted County, Minnesota. Gastroenterology 1997; 112:1448-1456.

8. Isolauri J, Laippala P. Prevalence of Symptoms Suggestive of Gastroesophageal Reflux Disease in an Adult Population. Ann Med 1995; 27: 67-70.

9. Delaney BC. Prevalence and epidemiology of gastro-oesophageal reflux disease. Aliment Pharmacol Ther 2004; 20: 2-4.

10. Wong BC, Kinoshita Y. Systematic review on epidemiology of gastroesophageal reflux disease in Asia. Clin Gastroenterol Hepatol. 2006; 4(4):398-407.

11. Klauser AG, Schindlbeck NE, Müller-Lissner SA. Symptoms in gastro-oesophageal reflux disease. Lancet 1990; 335: 205-208.

12. Hampel H, Abraham NS, El-Serag HB. Meta-Analysis: Obesity and the Risk for Gastroesophageal Reflux Disease and Its Complications. Ann Intern Med 2005; 143:199211.

13. Farup C, Kleinman L, Sloan S, et al. The Impact of Nocturnal Symptoms Associated With Gastroesophageal Reflux Disease on Health-Related Quality of Life. Arch Intern Med 2001; 161:45-52.

14. Wang R, Zou D, Ma X, Yanfang Z, Xiaovan Y, Hong Y. et al. Impact of gastroesophageal reflux disease on daily life: the Systematic Investigation of Gastrointestinal Diseases in China (SILC) epidemiological study. Health Qual Life Outcomes 2010; 8: 128. doi: 10.1186/1477-7525-8-128 PMCID: PMC2996363.

15. Hila A, Castell DO. Gastroesophageal reflux disease. Current Treatment Options in Gastroenterology 2003;6:41-48, DOI: 10.1007/s11938-003-0032-7 
Table 1: Symptom frequency

\begin{tabular}{lll}
\hline Symptom & GERD $\%$ & P value \\
\hline Burning in Chest & 72.2 & $<0.0001$ \\
Acid in Throat & 67.7 & $<0.0001$ \\
Burning in Stomach & 51.5 & $<0.0001$ \\
Food Reflux & 42.1 & $<0.0001$ \\
Awaken at night & 25.2 & $<0.0001$ \\
Dysphagia & 11.7 & $<0.0001$ \\
\hline
\end{tabular}

Table 2: Symptom severity

\begin{tabular}{lllll}
\hline Symptom & Mild $\%$ & Moderate $\%$ & Severe $\%$ & P-value \\
\hline Liquid Reflux & 75.6 & 20.9 & 3.4 & 0.014 \\
$\begin{array}{l}\text { Burning in } \\
\text { Chest }\end{array}$ & 65.8 & 30.8 & 3.3 & 0.011 \\
$\begin{array}{l}\text { Burning in } \\
\begin{array}{l}\text { Stomach } \\
\text { Acid in Throat }\end{array}\end{array}$ & 78.2 & 18.2 & 3.9 & 0.003 \\
$\begin{array}{l}\text { Food Reflux } \\
\text { Dysphagia }\end{array}$ & 79.7 & 16.1 & 3.6 & 0.023 \\
$\begin{array}{l}\text { Wake from } \\
\text { sleep }\end{array}$ & 64.7 & 20.3 & 4.2 & 0.168 \\
\hline
\end{tabular}

